\title{
Systematic Framework for Integration of Weather Data into Prediction Models for the Electric Grid Outage and Asset Management Applications
}

\author{
Mladen Kezunovic ${ }^{1}$, Zoran Obradovic ${ }^{2}$, Tatjana Dokic ${ }^{1}$, Shoumik Roychoudhury ${ }^{2}$ \\ ${ }^{1}$ Department of Electrical and Computer Engineering \\ Texas A\&M University \\ College Station, TX, U.S.A. \\ ${ }^{2}$ Computer and Information Sciences Department \\ Temple University \\ Philadelphia, PA, U.S.A.
}

\begin{abstract}
This paper describes a Weather Impact Model (WIM) capable of serving a variety of predictive applications ranging from real-time operation and dayahead operation planning, to asset and outage management. The proposed model is capable of combining various weather parameters into different weather impact features of interest to a specific application. This work focuses on the development of a universal weather impacts model based on the logistic regression embedded in a Geographic Information System (GIS). It is capable of merging massive data sets from historical outage and weather data, to real-time weather forecast and network monitoring measurements, into a feature known as weather hazard probability. The examples of the outage and asset management applications are used to illustrate the model capabilities.
\end{abstract}

\section{Introduction}

Unfolding weather conditions pose a major threat to the electricity networks due to their high level of deterioration susceptibility to weather elements [1]. Combined, $75 \%$ of power outages are either directly caused by weather-inflicted faults (e.g., lightning, wind impact causing surrounding vegetation to contact transmission lines), or indirectly by equipment failures due to wear and tear, partially due to weather exposure (e.g. prolonged overheating or exposure to lightninginduced over-voltages) [1].

The number and frequency of power outages is dramatically increasing [2]. Even though over $95 \%$ of outages are shorter than four hours [2], the US economy loses \$104-\$164 billion a year to outages and another $\$ 15$ - \$24 billion to power quality phenomena [3-5]. This proliferation of grid outages and associated surges is caused by "severe" weather due to high wind, lightning, snow/storm, floods, etc., which is caused by increased variability and extremes in seasonal weather patterns. The "Catastrophic" weather (hurricanes and tornadoes) accounts for only $7 \%$ of large blackouts [6], with more than $50 \%$ due to severe or extreme weather. The atmospheric conditions most conducive to severe weather are expected to increase [7-9]. This increase in non-catastrophic severe weather events is causing increases in outage frequency, resulting in huge economic, social, and environmental risks to power systems and its customers.

There have been some efforts to develop a weather impact assessment in recent years. The time-varying weight factors were introduced as a measure of weather impact to component failure rates and restoration times [10]. Historical weather data were correlated with historical outage data in order to develop a damage forecast model for restoration [11]. Variety of studies have been addressing the impact of extreme [12-14] and catastrophic $[15,16]$ weather on power system infrastructure. The impacts of large scale storms and hurricanes have been evaluated [12], while the risk analysis has been performed for evaluation of wind storm impacts [13]. The impacts of Hurricane Sandy have been evaluated as suggested in [14]. A probabilistic framework for assessment of extreme weather conditions impact on the grid [15], and also the system restoration after the extreme weather events is studied in [16].

There are two limitations of the existing weather impact methods that our paper is addressing: 1) although existing solutions have good performances for improving the post-outage restoration process, the predictive capabilities that would enable pro-active maintenance and operation are missing, and 2) most of the studies are focused on the extreme and catastrophic events, while there is a lack of a weather impact assessment for the daily severe weather conditions.

The targeted applications for weather hazard are described in Ch. 2. The overview of weather data sources is provided in Ch. 3 followed by $\mathrm{Ch} .4$ description of the design of the WIM. Predictive capabilities of the model are described in Ch. 5, while the results are reported in Ch. 6. Final conclusions are provided in Ch. 7. 


\section{Predictive Spatiotemporal Applications}

The assessment of weather impacts on power systems must be spatiotemporally granular (multi-level) to effectively deal with a continuity of evolving conditions. The knowledge needs to be presented in a spatiotemporal framework with highly accurate georeferencing and geo-analytics for correlating weather and physical layout of the electricity grid. Spatially and temporally coordinated measurements coming from both utility infrastructure and weather data sources need to scale to the temporal dynamics of the knowledge extraction process.

The predictive outage management framework offers automated tools for real-time decision making for weather related outages leading to the outage area prediction, fast outage location, efficient post-outage asset repair and timely network restoration procedures. With the knowledge of approaching weather hazards, one to several hours in advance, the appropriate outage mitigation or fast outage restoration strategies can be planned.

The predictive assets management framework evaluates weather impacts on deterioration and failure rates of utility assets such as insulators, surge arresters, power transformers, and circuit breakers providing knowledge for planning optimal maintenance and replacement schedules. Asset management typically deals with long-term analysis (days, months, years). Hazard maps generated continuously one to couple of days in advance provide an opportunity for creating proactive maintenance schedules leading to a decrease in probability of catastrophic asset failures and consequently cost savings.

\section{Weather Data}

Two types of weather impact are of particular interest to this study: 1) long-term weather impact on electricity network (expressed in days, months, years) such as prolonged exposure of assets to high seasonal temperatures, and 2) instantaneous impacts such as lightning strikes affecting utility assets and causing faults during storms. The focus of this paper is to assess impacts of day-to-day weather impacts, such as thunder storms, high winds, and significant temperature fluctuations. It is important to distinguish such cases from the assessment of catastrophic weather impacts where the predictions are focused on weather forecast only during the short time period of the catastrophic event. In our application, we observe variety of weather impacts that network is experiencing over time. Combined, these day-to-day weather impacts cause a majority of weather-related stresses on the network.

Overview of the weather data sources with various characteristics is presented in Table I. A variety of historical weather data shown in Table I is collected by different technologies: 1) land-based sensor measurement stations, 2) radio detection and ranging (Radar), and 3) satellite. The land-based stations collect

Table I. Weather Data Sources and Characteristics

\begin{tabular}{|c|c|c|c|c|c|c|}
\hline Source & $\begin{array}{l}\text { Data } \\
\text { Type }\end{array}$ & $\begin{array}{l}\text { Temporal } \\
\text { Coverage }\end{array}$ & $\begin{array}{c}\text { Spatial } \\
\text { Coverage }\end{array}$ & $\begin{array}{l}\text { Temporal } \\
\text { Resolution }\end{array}$ & $\begin{array}{c}\text { Spatial } \\
\text { Resolution }\end{array}$ & Measurements \\
\hline $\begin{array}{l}\text { Automated } \\
\text { Surface } \\
\text { Observing } \\
\text { System } \\
\text { (ASOS) [17] }\end{array}$ & $\begin{array}{l}\text { Land- } \\
\text { Based } \\
\text { Sensor } \\
\text { Stations } \\
\text { Data }\end{array}$ & $\begin{array}{l}2000- \\
\text { Present }\end{array}$ & USA & $1 \mathrm{~min}$ & $\begin{array}{c}900 \\
\text { stations }\end{array}$ & $\begin{array}{c}\text { Air Temperature, Dew Point, Relative } \\
\text { Humidity, Wind Direction, Wind Speed, } \\
\text { Altimeter, Sea Level Pressure, Precipitation, } \\
\text { Visibility, Wind Gust, Cloud Coverage, Cloud } \\
\text { Height, Present Weather Code } \\
\end{array}$ \\
\hline $\begin{array}{l}\text { Level-2 Next } \\
\text { Generation } \\
\text { Weather Radar } \\
\text { (NEXRAD) } \\
\text { [18] } \\
\end{array}$ & $\begin{array}{l}\text { Radar } \\
\text { Data }\end{array}$ & $\begin{array}{c}1991- \\
\text { Present }\end{array}$ & USA & $5 \mathrm{~min}$ & $\begin{array}{l}160 \text { high- } \\
\text { resolution } \\
\text { Doppler } \\
\text { radar sites }\end{array}$ & Precipitation and Atmospheric Movement \\
\hline $\begin{array}{c}\text { NOAA } \\
\text { Satellite } \\
\text { Database [19] }\end{array}$ & $\begin{array}{c}\text { Satellite } \\
\text { Data }\end{array}$ & $\begin{array}{l}1979 \text { - } \\
\text { Present }\end{array}$ & USA & $\begin{array}{l}\text { Hourly, } \\
\text { daily, } \\
\text { monthly }\end{array}$ & $4 \mathrm{~km}$ & $\begin{array}{l}\text { cloud coverage, hydrological observations } \\
\text { (precipitation, cloud liquid water, total } \\
\text { precipitable water, snow cover, and sea ice } \\
\text { extent), pollution monitoring, smoke detection, } \\
\text { surface temperature readings }\end{array}$ \\
\hline $\begin{array}{l}\text { Vaisala U.S. } \\
\text { National } \\
\text { Lightning } \\
\text { Detection } \\
\text { Network [20] }\end{array}$ & $\begin{array}{c}\text { Lightning } \\
\text { Data }\end{array}$ & $\begin{array}{c}1989- \\
\text { Present }\end{array}$ & USA & Instantaneous & $\begin{array}{l}\text { Median } \\
\text { Location } \\
\text { Accuracy } \\
<200 \mathrm{~m}\end{array}$ & $\begin{array}{l}\text { Date and Time, Latitude and Longitude, Peak } \\
\text { amplitude, Polarity, Type of event: Cloud or } \\
\text { Cloud to Ground }\end{array}$ \\
\hline $\begin{array}{l}\text { National } \\
\text { Digital } \\
\text { Forecast } \\
\text { Database } \\
\text { (NDFD) [21] }\end{array}$ & $\begin{array}{l}\text { Weather } \\
\text { Forecast } \\
\text { Data }\end{array}$ & $\begin{array}{l}\text { Present - } \\
7 \text { days } \\
\text { into future }\end{array}$ & USA & 3 hours & $5 \mathrm{~km}$ & $\begin{array}{c}\text { Wind Speed, Direction, and Gust, Temperature, } \\
\text { Relative Humidity, Convective Hazard Outlook, } \\
\text { Prob. Critical Fire, Prob. Dry Lightning, Hail } \\
\text { Probability, Tornado Probability, Probability of } \\
\text { Severe Thunderstorms, Damaging } \\
\text { Thunderstorm Wind Probability, Extreme Hail } \\
\text { Probability, etc. }\end{array}$ \\
\hline
\end{tabular}


variety of measurements at their location. The most precise measurement system is $1 \mathrm{~min}$ Automated Surface Observing System (ASOS) [17]. Radar uses radio waves to track storm movements where different radio wave reflectivity levels are presented as different colors on a map [18]. Satellites provide global environmental observations [19] such as cloud coverage, hydrological observations (precipitation, cloud liquid water, total precipitable water, snow cover, and sea ice extent), pollution monitoring, smoke detection, surface temperature readings, etc. Lightning data is collected by National Lightning Detection Network operated by Vaisala [20].

National Digital Forecast Database (NDFD) [21] provides weather prediction for variety of weather parameters as presented in Table I. NDFD uses Numerical Weather Prediction (NWP) models. Some of the models that are used for weather forecast and their capabilities are [22]: 1) Global Ensemble Forecast System (GEFS) uses 21 different forecasts to generate a global-coverage weather forecast model; 2) Global Forecast System (GFS) contains four different forecast models working together in order to provide accurate picture of weather changes; and 3) North American Mesoscale (NAM) weather forecast model developed for North America region is based on Weather Research and Forecast (WRF) model [23].

\section{Risk Analysis Based on Weather Impacts}

The use of risk management can decrease the number of outages and mitigate consequences through optimal management of the balance between an acceptable risk level and preventive maintenance strategy. The risk-based framework is a key to application of pro-active risk mitigation measures based on the optimal ranking of risk reduction factors. The weather-related risk analysis can be described as [24]:

$$
\mathrm{R}=\mathrm{H} \times \mathrm{V} \times \mathrm{I}
$$

where hazard $H$ defines the probability of a severe weather impact; vulnerability $V$ defines the probability of a certain event in the network occurring due to a severe weather condition; and $I$ is an impact of the event (economic and social). While vulnerability and impacts depend highly on application of interest, it is possible to develop a Hazard Model that could serve a variety of applications ranging from real-time operation and dayahead operation planning, to assets and outage management.

The proposed hazard model is capable of assessing the variety of weather and environmental impacts, and combining these impacts into a variety of measures of interest to each specific application. The process of building a weather hazard model input starts with the raw measurements taken by different sensors, such as temperature and wind speed sensors in land-based weather stations, as well as radar, and satellite weather observations. Since the data comes with different spatial and temporal resolutions, it is critical to correlate all the data as an input to a unified spatiotemporal model. As a result, a variety of features of interests can be extracted from such fused data. A selection of weather impacts of interest is based on a set of extracted features relevant to a given application.

Different applications may depend on different weather impacts. For example, the lightning protection application would primarily rely on the information about lightning, with the additional insight into temperature, pressure, humidity and precipitation data. On the other hand, the vegetation management application would be highly dependent on wind parameters and precipitation. An important characteristic of the model is its capability to generate the hazard value for different types of impacts tuned to the application of interest. The ultimate goal is to create a hazard probability for each moment in time.

\subsection{The WIM Testbed Architecture}

The WIM testbed or integration of Big Data related to weather impacts on electric transmission and distribution is presented in Fig. 1. The testbed is implemented using various commercial solutions, such as Mitsubishi wall display [25], OsiSoft PI Historian [26], and Esri GIS solution [27]. The PI Historian platform is used for temporal analysis and visualization. The ArcGIS and PI platforms are loaded with electric utility assets data and weather data from all the sources of interest. The wall display presents the analysis preformed on one or multiple operator consoles that may be configured for production type decision-making aimed at gaining either the operating or training experiences.

The developed extension to ArcGIS allows the integration and spatiotemporal correlation of the standard types of data and models, as well as novel data sources such as weather and vegetation data. The system provides interfaces to software packages such as MATLAB, OpenDSS, Anaconda (Jupyter) using Python. This testbed demonstrates how the traditional Big Data sources describing attributes of the power grid itself can be spatiotemporally correlated with novel Big Data sources describing the environment and other GIS and GPS features to enable solutions that provide better decision-making capabilities. The PI system provides a highly reliable data management infrastructure capable of handling large quantities of real-time data coming from weather data sources. The PI system enables long- 


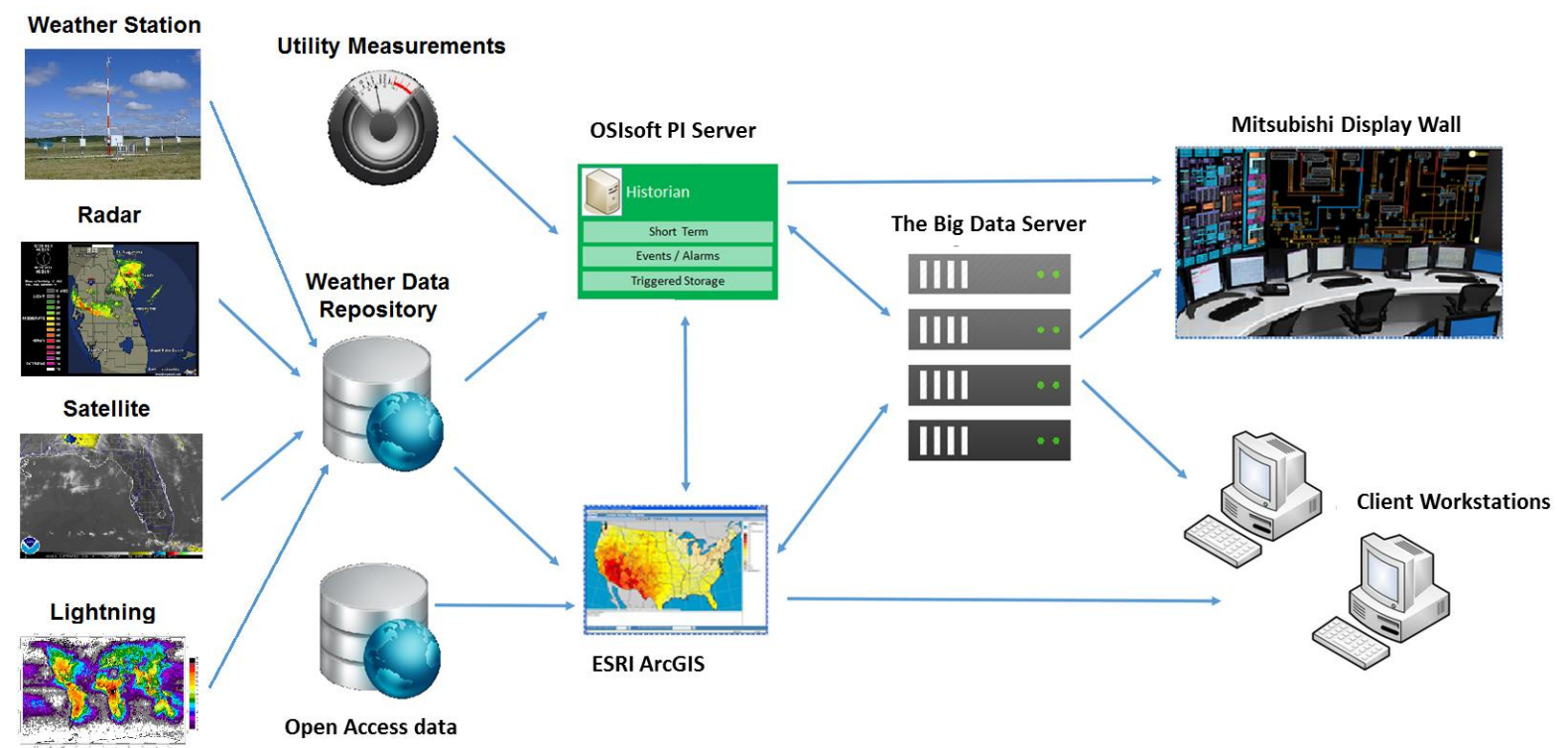

Figure 1. Overall architecture of the weather testbed solution

term data storing (PI historian), as well as flexible data analysis (PI ACE) for real-time decision making.

\subsection{Spatial Correlation of Data}

Spatial correlation of data is presented in Fig. 2. The locations of utility network assets are contained in the utility's geodatabase. This geodatabase is first extended with historical outage data that are geocoded into a point shapefile. Lightning data obtained from Vaisala contains geographical location in the csv file, which is converted to the lightning point shapefile, and added to the database. For each network tower, the lightning frequency is calculated from the historical data collected in the radius of $1 \mathrm{~km}$ around the tower.

Weather data is associated with the weather stations that are sparsely located over the area. Thus, the weather parameters need to be spatially interpolated in order to estimate their values at each location in the network. The network area is split into grid. The weather parameters are estimated for each grid cell based on the closest three weather stations' data.

For each lightning outage, the set of lightning strikes in its vicinity is generated and transmitted to the

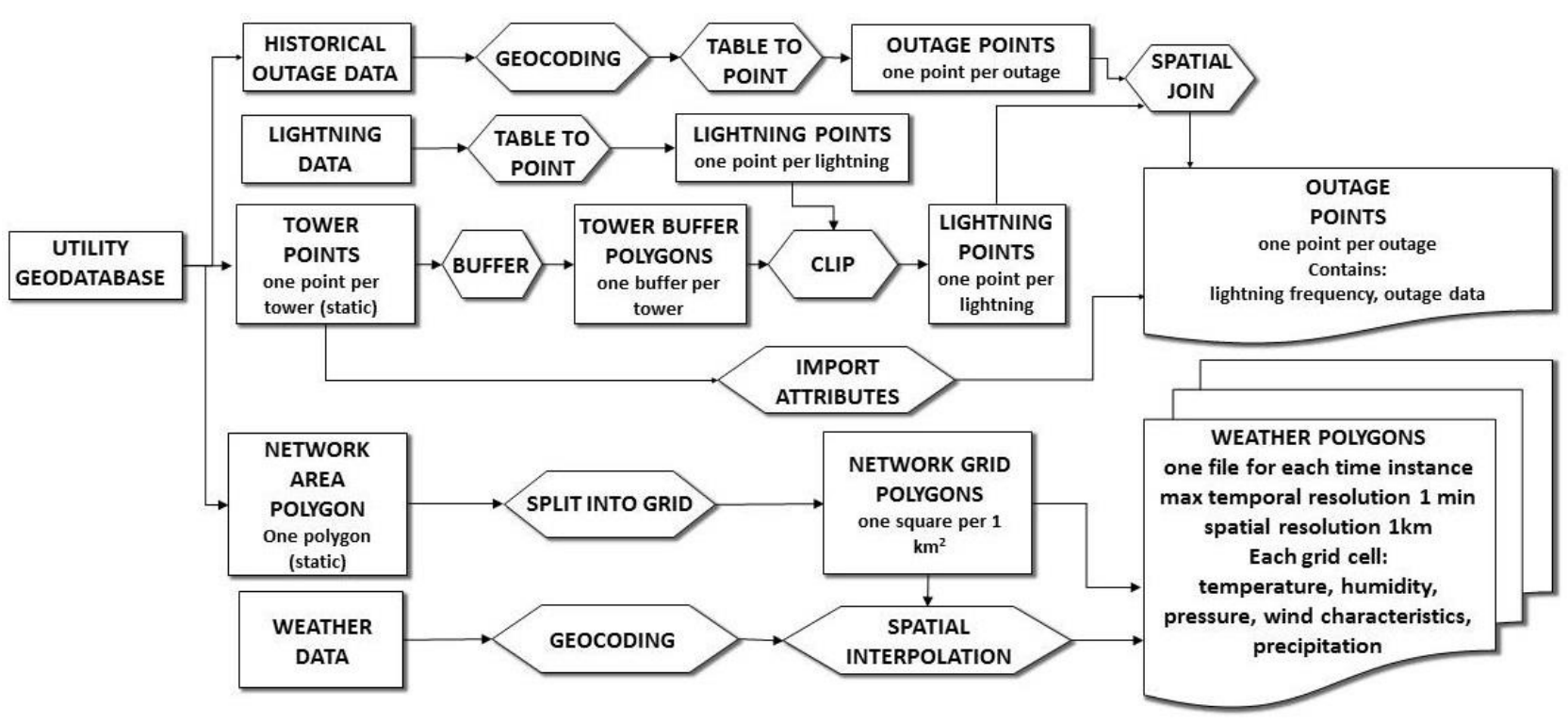

Figure 2. Spatial Correlation of Data 
temporal correlation procedure presented in the next section. This is the first step in determining which lightning strike is associated with which lightning caused outage.

The final output of the spatial correlation is a set of weather parameter maps for each observation, and a historical outage map with all the attributes integrated in the outage shapefile. These two databases are then transferred to the temporal correlation procedure that is described next.

\subsection{Temporal Correlation of Data}

Temporal correlation of data is presented in Fig. 3. The goal of temporal correlation is to associate all the necessary parameters with each historical outage. First, the time zone conversion is performed to ensure unique UTC time reference. Then, each outage is set through the loop that extracts the weather parameters based on the specified time of the outage. Different weather parameters come with different temporal resolutions and temporal accuracies. Therefore, it is necessary to perform linear interpolation to estimate the exact value of weather parameters at the time of an outage. For each outage occurrence, the two closest measurement moments are determined and used for the interpolation.

In case of lightning outages, the associated lightning strike is determined based on both the spatial and temporal closeness to the recorded historical outage, and all the lightning data for that lightning strike are imported to the outage file as they are (without interpolation).

The final product of the temporal analysis is a historical outage file containing all the necessary weather parameters for each outage. This file has all the necessary data for calculation of weather hazard for multiple applications. The outage file is then used in the prediction model presented in the next chapter.

\section{Logistic Regression Model}

The goal of the WIM prediction is to estimate an outage event with a probabilistic score (hazard probability) using the various forecasted weather parameters identified in the previous section as features related to an outage event (lightning, vegetation, etc.). A probabilistic interpretation of the outage event outcome shall provide an intuition to the operator who can decide the level of impact importance of the predicted event outcome. Thus, a probabilistic classifier is used for building the models reflecting desired relationship between weather parameters and outage events.

A binary classification model [29] is used to classify outage and no-outage events. The model can be described as the probability of an outage event (hazard probability) modelled as a Bernoulli distribution

$$
\mathrm{p}(\mathrm{y}=\text { outage event } \mid \mathbf{X}, \mathbf{w})=\operatorname{Ber}\left(\mathrm{y} \mid \sigma\left(\mathbf{w}^{\mathbf{T}} \mathbf{X}\right)\right.
$$

where input $\boldsymbol{X}$ is the set of attributes (weather parameters such as temperature, air pressure, wind direction, wind speeds etc.) and lightning current recorded during the outage event and $\boldsymbol{w}$ is the weight parameters of a linear function learned by minimizing a logistic loss function (eq. (4)). The output of an event is a probability score computed using a non-linear sigmoid function $\left(\sigma\left(\mathbf{w}^{\mathbf{T}} \mathbf{X}\right)\right)$.

$$
\mathrm{p}(\mathrm{y}=\text { outage event } \mid \mathbf{X}, \mathbf{w})=\sigma\left(\mathbf{w}^{\mathbf{T}} \mathbf{X}\right)
$$

The logistic loss function is defined as a negative log-likelihood function of the Bernoulli distribution.

$$
\begin{gathered}
\operatorname{Loss}(\mathrm{w})=-\sum y \log \left(\sigma\left(\mathbf{w}^{\mathrm{T}} \mathbf{X}\right)\right) \\
+(1-\mathrm{y}) \log \left(1-\left(\sigma\left(\mathbf{w}^{\mathbf{T}} \mathbf{X}\right)\right)\right.
\end{gathered}
$$

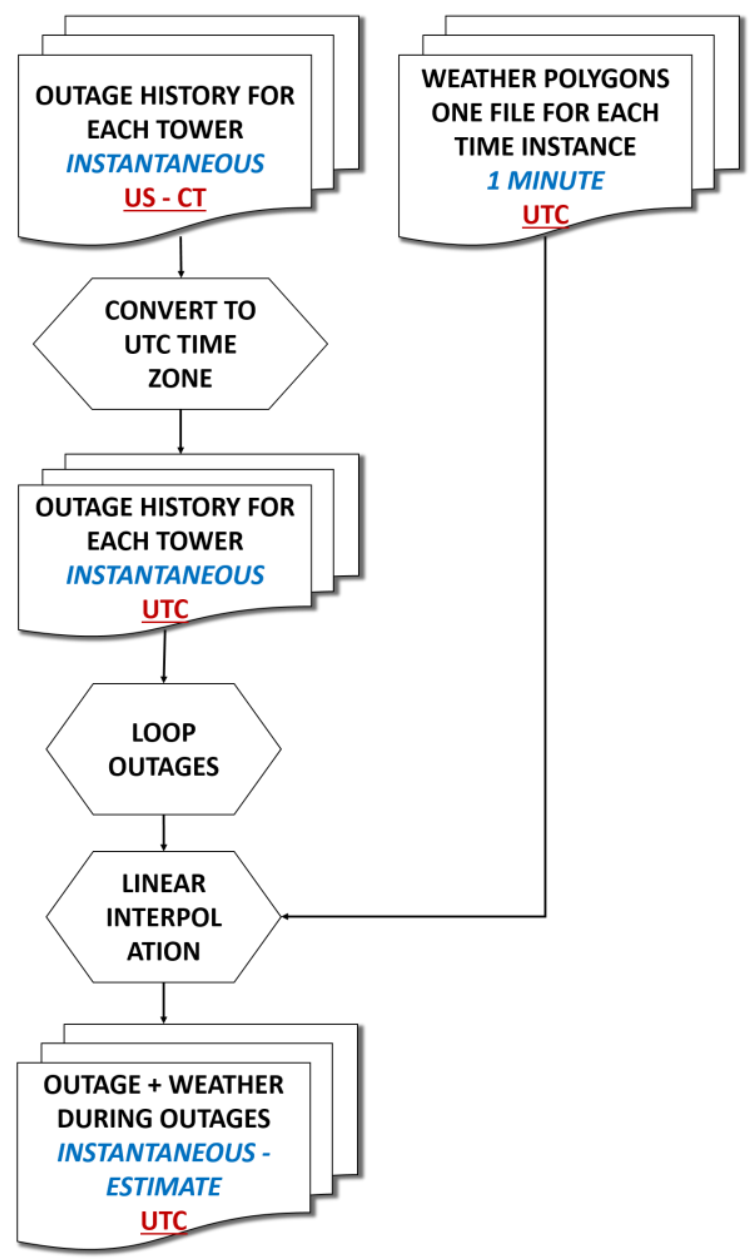

Figure 3. Temporal Correlation of Data 
The loss function is convex and can be minimized using gradient descent methods [30] for an unconstrained optimization.

In our study, three types of hazard outage features are modelled using logistic regression, corresponding to lightning outage, vegetation outage and other outages.

\section{Evaluation and Results}

The system is tested on a part of utility distribution network covering an area of $\sim 2,000 \mathrm{~km}^{2}$. The system consists of $\sim 200,000$ poles, and $\sim 60,000$ lines. The historical outage and weather data was collected for the period from the beginning of 2011 up to the end of 2015. Over these five years, 505 weather related outages have been observed in the area. Table II summarizes the outage history.

\subsection{Testbed Experimental Setup}

In order to verify the proposed classification model we conducted a series of cross validation experiments. Three sets of datasets were extracted from the historical outage file each signifying a particular hazard event (lightning, vegetation and other outages). Each dataset consists of 505 hazard events where the attribute of each event is denoted by $\boldsymbol{X}$ which consists of nine weather and lightning parameters, namely AirTemperature, DewPoint, RelativeHumidity, WindDirection, WindSpeed, Pressure, Precipitation, WindGust, and LightningCurrent. The output for each dataset is $y \in$ $\{0,1\}$ indicating the occurrence or non- occurrence of the desired hazard event. 5-fold cross-validation experiments were conducted for each dataset and for each fold the Area under the Curve (AUC) [28] was reported (e.g. blue line in Fig. 5).

The average $A U C$ over 5 folds is also reported. Fig. 5, 7 and 9 represent the Receiver Operating characteristic Curve (ROC curve) [28] for each the model learned for each of the 5-folds on the three hazard datasets. $R O C$ curve is a graphical plot that illustrates the diagnostic ability of a binary classifier system as its discrimination threshold (hazard probability threshold) is varied. The true positive rate or sensitivity is plotted on the $Y$-axis against the false-positive rate or (1 specificity) on the $X$-axis. The top left-most corner of the $R O C$ plot indicates perfect classification results with an $A U C$ of 1 . Thus, $A U C$ measure can be used to evaluate the performance of the classifier.

\subsection{Weather Hazard for Lightning Impacts}

The weather hazard for asset management is demonstrated on the transmission tower insulator coordination application. The main hazard is considered to be lightning, and only the lightning caused outages are observed by the prediction model. The weather hazard is the probability of a lightning caused outage on a specific tower in the network.

The goal of asset management task is to assess the risk for each individual insulator in the network for each moment in time. Thus, the output of the developed hazard prediction model is used to calculate the risk for each individual tower and the results are presented as the point risk map in Fig. 4. In Fig. 5 the $R O C$ analysis of 5-fold cross-validation along with $A U C$ for each fold

Table II. Historical weather caused outages

\begin{tabular}{|l|c|c|}
\hline Type & Count & Outages Impact \\
\hline vegetation & 321 & 0.072 \\
\hline lightning & 120 & 0.017 \\
\hline other & 64 & 0.069 \\
\hline total & 505 & 0.058 \\
\hline
\end{tabular}

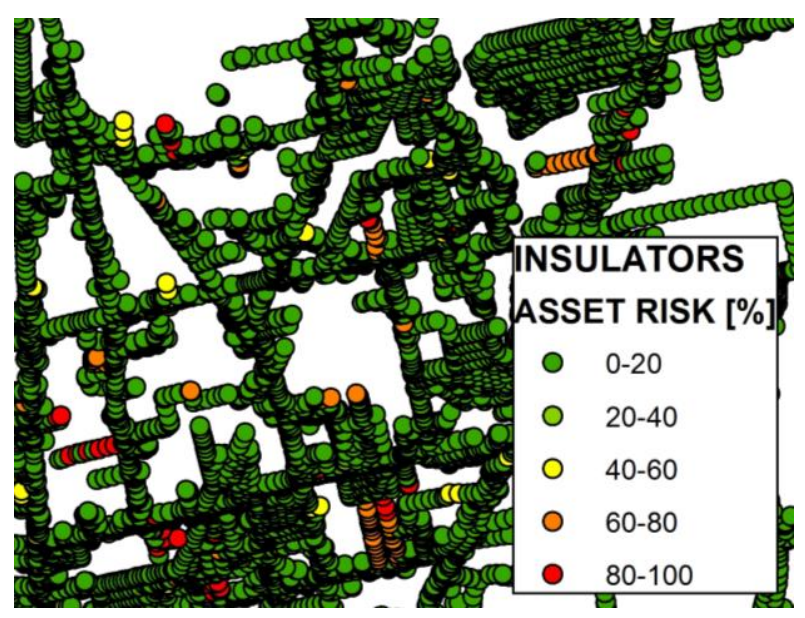

Figure 4. Asset Management Risk Map

ROC for Classification by Logistic Regression (Avg AUC:0.84)

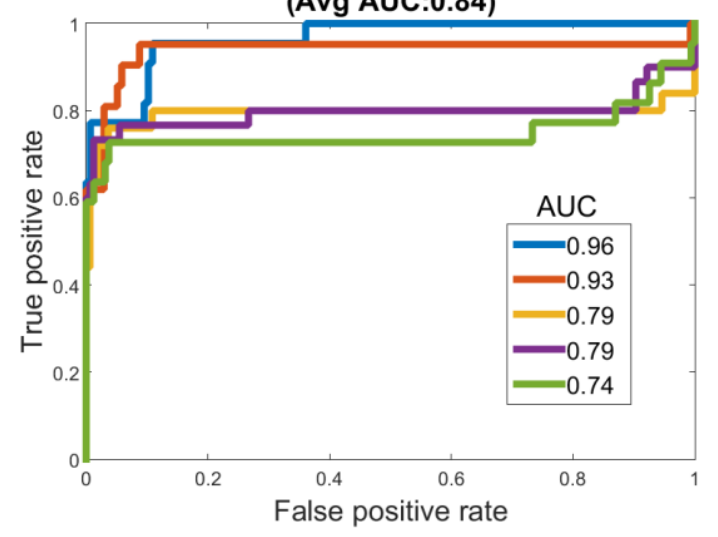

Figure 5. AUC for 5-fold cross validation on lightning outage dataset. 
and the average $A U C$ is reported. It is observed that a high true positive rate can be achieved for detecting lightning hazard while keeping a small false positive rate. The average $A U C$ is 0.85 .

\subsection{Weather Hazard for Vegetation Impacts}

The weather hazard for outage management is illustrated with the vegetation outage application. The hazard is the probability of an outage caused by combination of vegetation growth and tree limb movement under severe weather conditions.

The benefit for the outage management task is the prediction of the tree trimming section where the outage is expected to happen. This allows for the proactive maintenance of the targeted area to prevent the outage. Alternatively, the maintenance crew can be directed to the vulnerable network area and wait for the outage to happen in order to provide fast restoration response. The output of the hazard model is used to calculate the risk associated with each tree trimming zone. Example of the result is presented in Fig. 6. The ROC analysis for classification model on the vegetation dataset (Fig. 7) shows an average $A U C$ of 0.7564 . As observed from the $R O C$ analysis, significant amounts of false positive rate need to be accepted to achieve higher true positive rates.

\subsection{Weather Hazard for All Weather-Related Outages}

In this example, all weather outages are considered. The distribution operator is interested in knowing about any potential weather-related threat to the network. The results of the analysis need to be presented in a way that would allow for a quick and optimal decision making in case of unfolding weather conditions.

The hazard prediction is used to calculate the risk for the network areas in case of any kind of weather event. The recommendations about the network zones that are expected to have the maximum weather impact in the specific moment of time are made to the operator. The example is presented in Fig. 8. The ROC analysis for other outages besides lightning and vegetation is shown in Fig. 9. The average $A U C$ is 0.88 across 5-fold crossvalidation datasets and visually it is observed that close to $80 \%$ true positive rate can be achieved with less than $10 \%$ false positive rate.

\subsection{Evaluation of Unified Hazard Model}

In all cases, using unified logistic regression model based on all the input weather parameters shows better performances than observing individual applications separately. The Table III presents the comparison between average $A U C$ for cases where all the data are

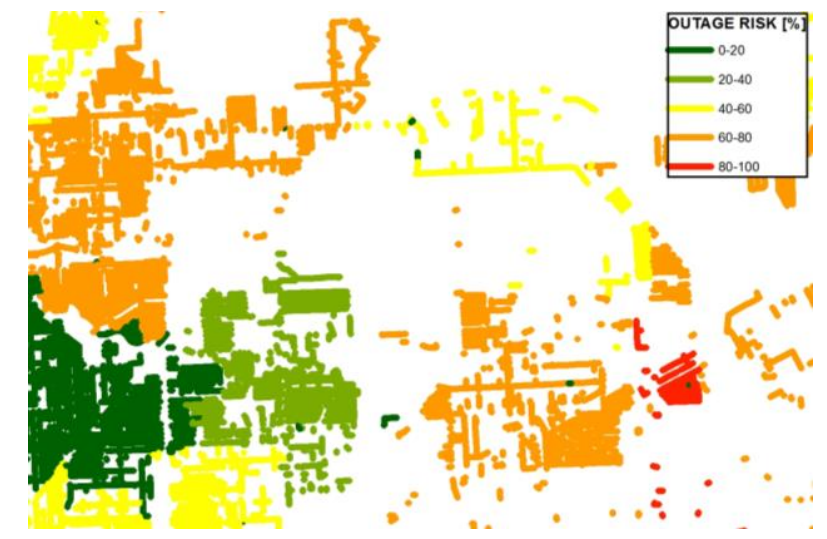

Figure 6. Outage Management Risk Map

ROC for Classification by Logistic Regression (Avg AUC:0.75)

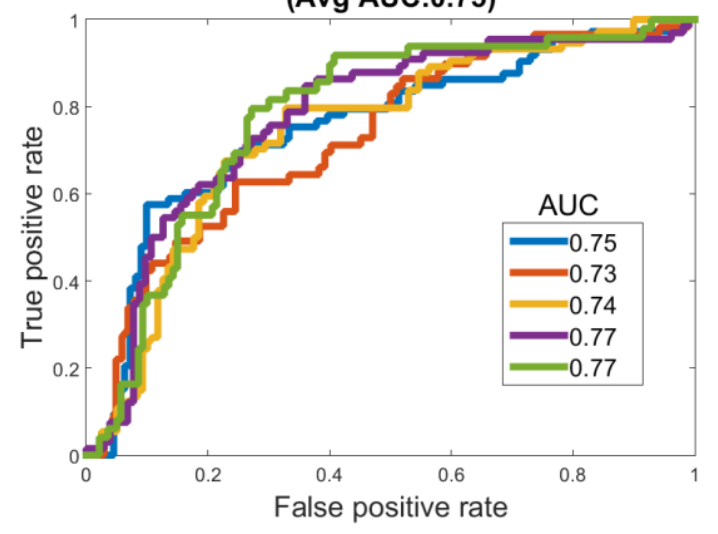

Figure 7. AUC for 5-fold cross validation on vegetation outage dataset.

used as part of unified prediction model versus the cases where only specific subset relevant to an application is used. This confirms the benefit of the unified weather hazard modeling within the utility that would serve all the departments. Fig. 10 presents the predicted hazard probabilities for multiple events in year 2015. Two cases were separated for each outage type: one where the outage occurred and one where there was no outage. From the Fig. 10 a) it can be observed that for most lightning outage occurrences the corresponding predicted hazard value is higher than the predicted hazard value in the periods when there was no lightning outage. In case of vegetation caused outages, the prediction accuracy is not as good as in case of lightning. It is important to observe that this work's focus is on prediction based only on weather data. The vegetation data was not taken into account in this study and it is left for future work. With accurate vegetation data, the accuracy of prediction in case of vegetation caused outages is expected to improve. 


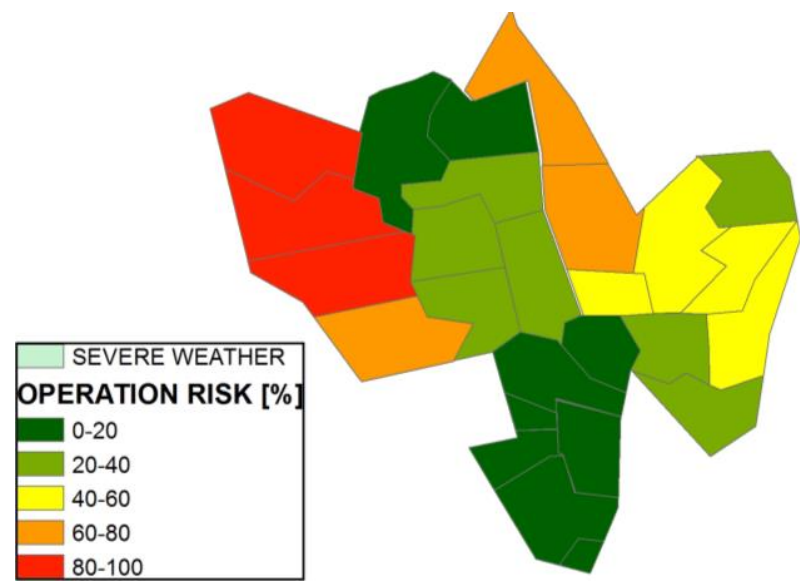

Figure 8. Operation Risk Map

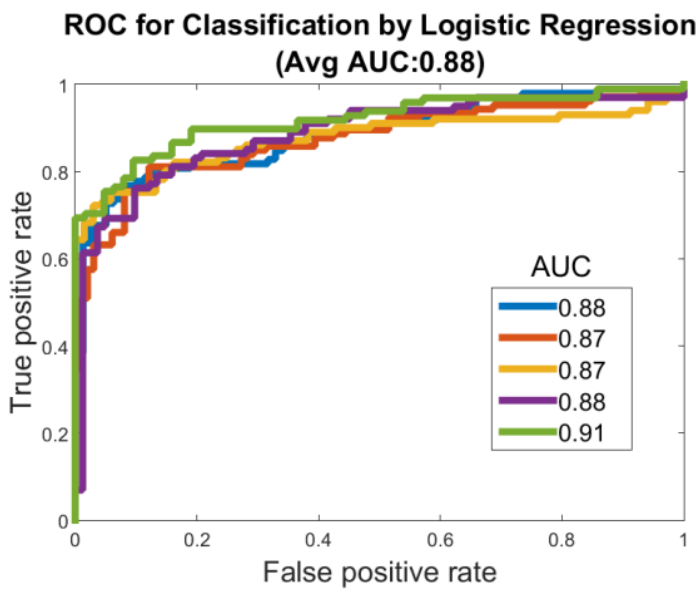

Figure 9. AUC for 5-fold cross validation on all outage dataset.

Table III. Average AUC depending on the dataset

\begin{tabular}{|c|c|c|}
\hline & $\begin{array}{c}\text { Lightning } \\
\text { Outages }\end{array}$ & $\begin{array}{c}\text { Vegetation } \\
\text { Outages }\end{array}$ \\
\hline All variables & 0.84 & 0.75 \\
\hline $\begin{array}{c}\text { Lightning } \\
\text { variables only }\end{array}$ & 0.83 & $*$ \\
\hline $\begin{array}{c}\text { Vegetation } \\
\text { variables only }\end{array}$ & $*$ & 0.69 \\
\hline
\end{tabular}

The Tables IV, V, and VI show the significance of predicting weather parameters for the three applications. For the lightning dataset, the p-values for AirTemperature, RelativeHumidity, Pressure and WindGust are small thus have high predictive power for lightning outage classification. Also, LightningCurrent has a small p-value, which means it is highly significant. In Table $\mathrm{V}$ for vegetation dataset, WindGust and WindSpeed has very low p-values, which is intuitive as mostly vegetation outage would be related to wind gust speeds. It is interesting to see that LightningCurrent also has a very small p-value. This case can be explained by how the outage may have unfolded due to a tree falling; however, the tree might have broken due to a lightning strike. In Table VI we find p-values for all the parameters to be low, which is also intuitive because other outages are possible for several weather factors which are not necessarily directly labeled as lightning or vegetation outage. In any case, some weather element must be the reason for the outage.

Table IV. Predictive significance of weather parameters for lightning outages

\begin{tabular}{|c|c|c|}
\hline Lightning Dataset & p-values & Parameter weight \\
\hline LightningCurrent & $3.99 \mathrm{E}-18$ & -1.737 \\
\hline RelativeHumidity & 0.008 & 2.188 \\
\hline WindGust & 0.013 & 0.364 \\
\hline Pressure & 0.028 & 0.358 \\
\hline WindDirection & 0.052 & -0.268 \\
\hline AirTemperature & 0.053 & 2.184 \\
\hline DewPoint & 0.122 & -1.797 \\
\hline WindSpeed & 0.237 & -0.178 \\
\hline Precipitation & 0.661 & -0.046 \\
\hline
\end{tabular}

Table V. Predictive significance of weather parameters for vegetation outages

\begin{tabular}{|c|c|c|}
\hline Vegetation Dataset & p-values & Parameter weight \\
\hline WindGust & $1.53 \mathrm{E}-10$ & 0.694 \\
\hline LightningCurrent & $2.52 \mathrm{E}-07$ & 0.739 \\
\hline WindSpeed & 0.0009 & -0.352 \\
\hline Pressure & 0.020 & -0.203 \\
\hline RelativeHumidity & 0.112 & 0.649 \\
\hline Precipitation & 0.158 & -0.130 \\
\hline DewPoint & 0.283 & -0.596 \\
\hline AirTemperature & 0.405 & 0.439 \\
\hline WindDirection & 0.622 & -0.042 \\
\hline
\end{tabular}

Table VI. Predictive significance of weather parameters for other outages

\begin{tabular}{|c|c|c|}
\hline Other outage Dataset & p-values & Parameter weight \\
\hline WindGust & $1.89 \mathrm{E}-27$ & 2.294 \\
\hline WindSpeed & $4.18 \mathrm{E}-15$ & -1.461 \\
\hline RelativeHumidity & 0.0001 & 1.840 \\
\hline DewPoint & 0.001 & -1.980 \\
\hline Precipitation & 0.002 & 2.396 \\
\hline AirTemperature & 0.003 & 1.776 \\
\hline Pressure & 0.003 & -0.321 \\
\hline WindDirection & 0.013 & -0.281 \\
\hline LightningCurrent & 0.047 & -0.319 \\
\hline
\end{tabular}




\section{Conclusion}

The paper describes the implementation of a unified weather hazard framework by developing a WIM capable of predicting severe weather impacts. Following are the main contributions of our study:

- An interface to the variety of weather data sources has been developed, including historical weather (land-based station, radar, satellite), and weather forecast models.

- The design of a large-scale WIM evaluation testbed implementation for the utility control center decision-making has been presented.

- The spatial and temporal correlation of weather data mapped to the utility outage data is demonstrated.

- The logistic regression model has been used to calculate the hazard probabilities for different types of weather caused outages.
- The proposed prediction model shows promising results where the average AUC is larger than 0.75 for all cases.

- The unified prediction model shows better results than models developed for the individual applications.

- The predictive significance of different weather parameters for the observed applications has been calculated.

- The use of the WIM to improve weather hazard predictions is presented with two examples: 1) Outage management: identification of the network zone under the high risk of weather related outages, and 2) Asset management: identification of assets that are the most likely to be affected by severe weather.
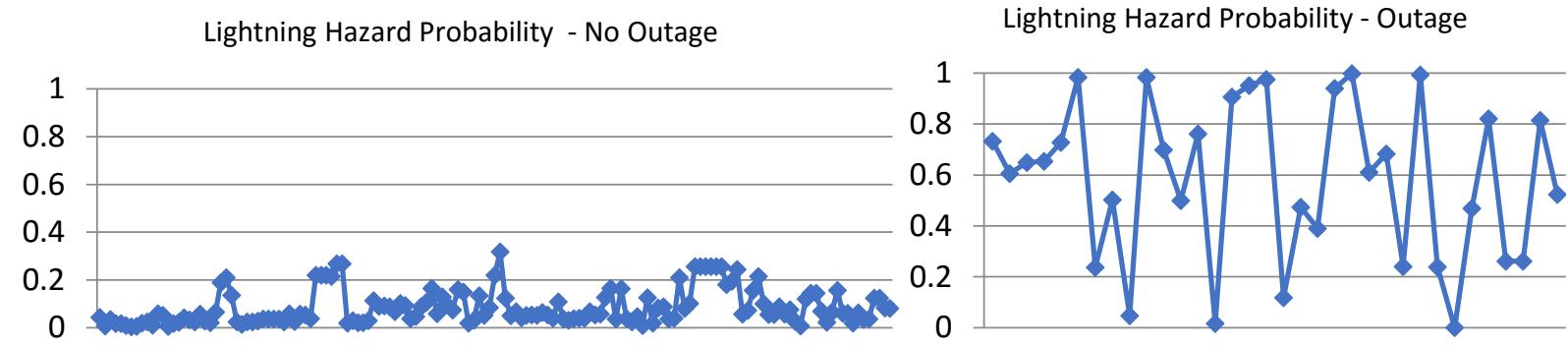

a)
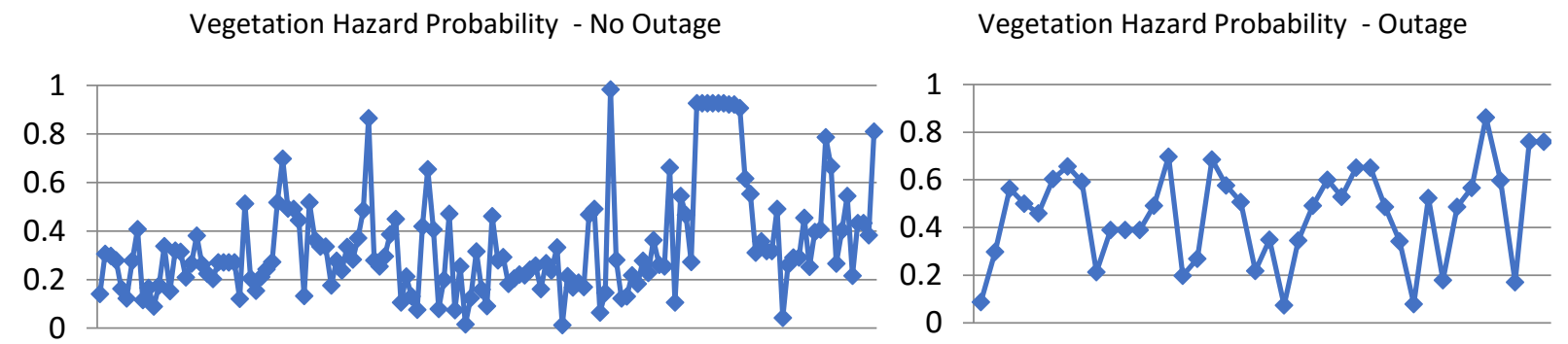

b)

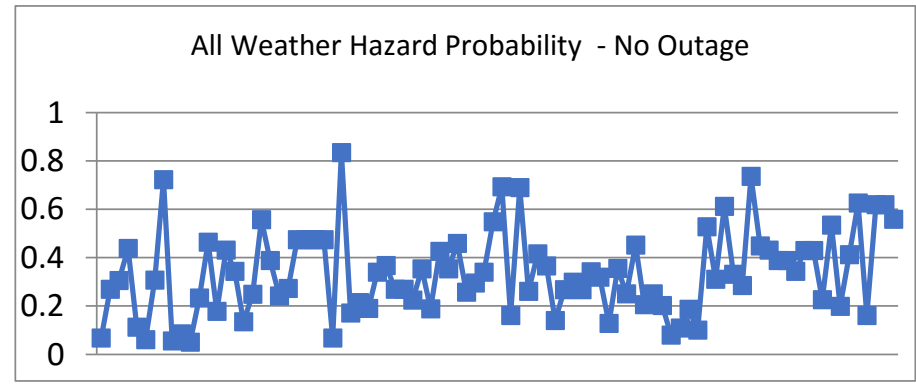

All Weather Hazard Probability - No Outage

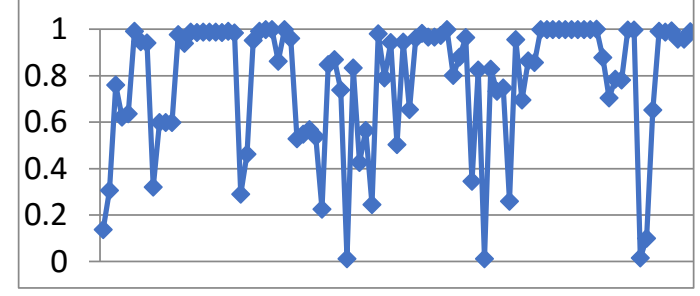

c)

Figure 10. Hazard probabilities predicted in 2015 based on the training data from 2011 to 2014 for a) lightning, b) vegetation, and c) all weather outages. 


\section{References}

[1] Eaton, "Blackout Tracker United States Annual Report 2013, “ Eaton, 2014. [Online] Available:

http://pqlit.eaton.com/ll_download_bylitcode.asp?doc_ id $=24005$

[2] Executive Office of the President, "Economic Benefits of Increasing Electric Grid Resilience to Weather Outages," Aug. 2013. [Online] Available: http://energy.gov/sites/prod/files/2013/08/f2/Grid\%20 Resiliency\%20Report_FINAL.pdf

[3] K. Darrow, et al., "The Role of Distributed Generation in Power Quality and Reliability," New York State Energy Research and Development Authority, Dec. 2005. [Online] Available: http://web10420.aiso.net/ documents/reportonyserdareliability.pdf

[4] Primen, "The Cost of Power Disturbances to Industrial \& Digital Economy Companies," EPRI's Consortium for Electric Infrastructure for a Digital Society (CEIDS), June 2001. [Online] Available: http://www. onpower.com/pdf/epricostofpowerproblems.pdf

[5] R. J. Campbell, "Weather-Related Power Outages and Electric System Resiliency, " CRS Report to Congress R42696. Washington, D.C., Congressional Research Service, 2012.

[6] P. Hines, et al., "Trends in the History of Large Blackouts in the United States, "IEEE Power and Energy Society General Meeting, IEEE, 2008.

[7] R. J. Trapp, et al., "Changes in severe thunderstorm environment frequency during the 21 st century caused by anthropogenically enhanced global radiative forcing, "PNAS, vol. 104, no. 50, pp. 19719-19723, doi:10.1073/pnas.0705494104, 2007.

[8] A. D. Del Genio, et al., "Will moist convection be stronger in a warmer climate? " Geophys. Res. Lett., Vol. 34, No. 16, doi:10.1029/2007GL030525, 2007.

[9] N. S. Diffenbaugh, et al., "Robust increases in severe thunderstorm environments in response to greenhouse forcing, " Proceedings of the National Academy of Sciences, vol. 110, pp. 16361-16366, doi:10.1073/pnas.1307758110, 2013.

[10] P. Wang, and Roy Billinton. "Reliability cost/worth assessment of distribution systems incorporating timevarying weather conditions and restoration resources." IEEE Transactions on Power Delivery, vol. 17, no. 1, pp. 260-265, 2002.

[11] L. Treinish et al., "Operational utilization and evaluation of a coupled weather and outage prediction service for electric utility operations," in Proc. 2nd Conf. Weather Climate New Energy Economy, Seattle, WA, USA, Jan. 2011.

[12] D. Lubkeman, and D. E. Julian. "Large scale storm outage management." Power Engineering Society General Meeting, 2004. IEEE. IEEE, 2004.

[13] G. Li, , et al. "Risk analysis for distribution systems in the northeast US under wind storms." IEEE Transactions on Power Systems, vol. 29, no. 2, pp. 889-898, 2014
[14] D. Yates, et al. "Stormy weather: Assessing climate change hazards to electric power infrastructure: A Sandy case study." IEEE Power and Energy Magazine, vol. 12, no. 5, pp. 66-75, 2014.

[15] M. Panteli, et al. "Power System Resilience to Extreme Weather: Fragility Modelling, Probabilistic Impact Assessment, and Adaptation Measures." Accepted to IEEE Transactions on Power Systems, 2016.

[16] C. Chen, et al., "Modernizing Distribution System Restoration to Achieve Grid Resiliency Against Extreme Weather Events: An Integrated Solution," accepted to Proceedings of the IEEE , 2017.

[17] National Oceanic and Atmospheric Administration, "Automated Surface Observing System (ASOS)," [Online] Available: https://www.ncdc.noaa.gov/dataaccess/land-based-station-data/land-baseddatasets/automated-surface-observing-system-asos

[18] National Oceanic and Atmospheric Administration, "Radar Data in the NOAA Big Data Project," [Online] Available: https://www.ncdc.noaa.gov/dataaccess/radar-data/noaa-big-data-project

[19] National Oceanic and Atmospheric Administration, "Satellite Data," 2017 [Online] Available: https://www.ncdc.noaa.gov/data-access/satellite-data

[20] Vaisala, "National Lightning Detection Network Technical Specification," 2017 [Online] Available: http://www.vaisala.com/en/products/thunderstormandli ghtningdetectionsystems/Pages/NLDN.aspx

[21] National Digital Forecast Database (NDFD) Tkdegrib and GRIB2 DataDownload and ImgGen Tool Tutorial, NWS, NOAA. 2017 [Online] Available: http://www.nws.noaa.gov/ndfd/gis/ndfd_tutorial.pdf

[22] National Centers for Enviromental Information National Oceanic and Atmospheric Sdministration, "Numerical Weather Prediction," 2017 [Online] Available: https://www.ncdc.noaa.gov/dataaccess/model-data/modeldatasets/numerical-weatherprediction

[23] Weather Recearch and Forecast Model, 2017 [Online] Available: http://www.wrf-model.org/index.php

[24] T. Dokic, et al., "Risk Assessment of a Transmission Line Insulation Breakdown due to Lightning and Severe Weather," HICCS - Hawaii International Conference on System Science, Kauai, Hawaii, January 2016.

[25] Mitsubishi Eectric, "D-wall," 2017 [Online] Available: https://www.mitsubishielectricdisplaysolutions.com/products/software/d-wall

[26] OSISoft, 2017 [Online] Available: http://www.osisoft.com/

[27] ArcGIS, Esri. 2017 [Online] Available: https://www.arcgis.com

[28] T. Fawcett, "An introduction to ROC analysis," Pattern Recognition Letters, vol. 27, pp. 861-874, 2006.

[29] K. Murphy, "Logistic regression," Machine Learning: A Probabilistic Perspective, Chapter 8, pp. $245-279$, 2012.

[30] S. Boyd, and L. Vandenberghe, "Convex Optimization,” 2004, ISBN: 9780521833783. 